\title{
SIMULAÇÓES, ASTRONOMIA, DIVULGAÇÃO DA CIÊNCIA E EDUCAÇÃO CIENTÍFICA
}

\author{
Rafael Brock Domingos ${ }^{1}$ \\ Ryan Nepomuceno Montemor ${ }^{2}$ \\ Ricardo Roberto Plaza Teixeira ${ }^{3}$
}

\begin{abstract}
Resumo: Este artigo faz uma análise das potencialidades existentes no uso didático de três softwares de simulação elaborados para o ensino de conceitos científicos: "Stellarium", "Monte um átomo" do "PhET - Interactive Simulations" e "Exoplanet Transit Hunt". Durante a investigação foram estruturadas e realizadas apresentações de divulgação científicas sobre temas de astronomia, astrofísica e cosmologia que se utilizaram estes softwares. São relatadas experiências envolvidas nas açóes que ocorreram em 2018 e em 2019, em instituiçôes de ensino do litoral norte paulista, a partir das parcerias desenvolvidas com o campus de Caraguatatuba do Instituto Federal de São Paulo (IFSP). A fundamentação teórica para as atividades realizadas foi feita a partir de uma revisão bibliográfica sobre a literatura científica existente sobre os temas em questão, em livros, artigos de revistas especializadas, trabalhos apresentados em congressos acadêmicos, dissertaçóes de mestrado e teses de doutorado. As atividades realizadas evidenciaram que os três softwares utilizados colaboraram consideravelmente com a compreensão dos conceitos científicos envolvidos. As açóes permitiram notar também um grande interesse por temas de astronomia pelos alunos da educação básica, o que é algo que deve ser considerado na elaboração de estratégias para a melhoria da educação científica nas escolas de ensino fundamental e médio.
\end{abstract}

Palavras-chave: divulgação científica; modelagem; astrofísica.

\section{SIMULATIONS, ASTRONOMY, SCIENCE OUTREACH AND SCIENCE EDUCATION}

\begin{abstract}
This article analyzes the existing potential for the didactic use of three simulation software designed to teach scientific concepts: "Stellarium", "Build an atom" from "PhET - Interactive Simulations" and "Exoplanet Transit Hunt". During the investigation, scientific dissemination
\end{abstract}

1 Graduando em Licenciatura em Física do IFSP, Campus Caraguatatuba.

2 Graduando em Licenciatura em Física do IFSP, Campus Caraguatatuba.

3 Doutor em Física pela USP e docente do IFSP, Campus Caraguatatuba. 
presentations on astronomy, astrophysics and cosmology were structured and made using these softwares. Experiences related to the actions that took place in 2018 and 2019 in educational institutions on the north coast of São Paulo are reported, based on the partnerships developed with the Caraguatatuba campus of the Federal Institute of Sáo Paulo (IFSP). The theoretical basis for the activities carried out was based on a bibliographic review of the existing scientific literature on the themes in question, in books, papers from specialized journals, works presented at academic congresses, master's dissertations and doctoral theses. The activities carried out showed that the three software programs used collaborated considerably with the understanding of the scientific concepts involved. The actions also made it possible to note a great interest in astronomy themes by students of basic education, which is something that must be considered in the elaboration of strategies to improve science education in elementary and high schools.

Keywords: science outreach; modeling; astrophysics.

\section{INTRODUÇÃO}

Este artigo procura relatar e investigar experiências de divulgação científica que permitiram analisar as potencialidades existentes no uso de três softwares de simulação elaborados para o ensino de conceitos científicos: "Stellarium", "Monte um átomo" do "PhET - Interactive Simulations" e "Exoplanet Transit Hunt". O seu principal objetivo é avaliar como a utilização destes programas pode colaborar para uma melhor formação científica dos alunos em geral. Após a introdução deste artigo, são analisados alguns referenciais teóricos acerca de áreas como ensino de astronomia e divulgação científica. Na sequência são abordados trabalhos acadêmicos que discutem acerca da importância do uso de simulações na educação científica e são descritos diferentes aspectos dos três softwares tratados neste artigo. Posteriormente, são caracterizadas tanto as atividades de divulgação científica realizadas utilizando estes softwares, quanto os seus resultados em termos educacionais. Ao término, nas consideraçôes finais são retomadas algumas questôes tratadas ao longo do artigo e apresentadas algumas conclusóes e indicaçôes a respeito do trabalho com simulações na educação científica.

O uso das novas Tecnologias da Informação e Comunicação (TICs) em práticas educacionais vem se intensificando com os anos (MIRANDA, 2007). As TICs envolvem recursos de aprendizagem que podem ajudar a desenvolver ambientes educacionais inovadores e propícios para uma aprendizagem efetiva, mas elas por si só náo têm o condáo de influenciar positivamente o desempenho dos estudantes: para isto ocorrer é fundamental o fator humano relacionado ao desempenho do professor na criaçáo de atividades desafiadoras e criativas que permitam explorar ao máximo as possibilidades oferecidas pelas tecnologias.

As simulaçóes computacionais no ensino iniciaram-se em campos nos quais estas práticas se mostravam inicialmente mais promissoras, como, por exemplo, a área médica (BRADLEY, 2006; FLATO; GUIMARÃES, 2011). Os softwares educacionais com simulaçóes computacionais têm se tornado crescentemente acessíveis e, inclusive, em muitos casos, de acesso gratuito. Mas o uso destas novas tecnologias inevitavelmente altera os papéis desempenhados por professores e estudantes dentro da sala de aula (RIBEIRO; GRECA, 2003). Estes tipos de 
ferramentas computacionais permitem explorar novas estratégias de ensino, ao possibilitar que os alunos percebam a relação causal entre as variáveis, pelo isolamento de um parâmetro por vez, o que por sua vez faz com que determinadas hipóteses explicativas possam ser testadas diretamente pelos alunos nas atividades de modelagem envolvidas.

As simulaçôes computacionais ao serem usadas como ferramentas auxiliares no processo de ensino-aprendizagem tornam possível explorar o que ocorre quando alteramos algumas das diversas grandezas de um sistema físico e permitem explicar com maior facilidade o que é observado a partir dos conceitos científicos envolvidos; quando isto é acompanhado pela reflexão e pelo questionamento sistemático, pode de fato superar o ensino mecanizado, tornando mais significativos os conteúdos aprendidos (SANTOS; OTERO; FANARO, 2000).

\section{ENSINO DE ASTRONOMIA E DIVULGAÇÃO CIENTÍFICA}

O ensino de astronomia é uma prática social que tem se expandido com o passar do tempo (CHASSOT, 2003). É importante que a formação escolar básica permita ao cidadão conhecer minimamente o consenso científico atual sobre a constituição e a história do universo. Há uma componente filosófica que nos aproxima e que está também implícita nesta tarefa: o conhecimento sobre a origem do cosmos permite refletir sobre a situação cósmica de "igualdade química" entre os seres humanos, pois somos todos igualmente feitos de "poeira de estrelas". Este trabalho trata das especificidades relacionadas à divulgação científica de temas como a formação e evolução dos planetas, das estrelas, das galáxias e do universo, com a história da ciência sendo utilizada de modo valioso como forma de contextualizaçáo.

A astronomia desempenhou um papel fundamental para a formação das sociedades humanas, pois observar os movimentos das estrelas e dos planetas no céu noturno é uma prática milenar (DAMINELI; STEINER, 2010). O conhecimento acerca de noçóes básicas de astronomia permite ampliar a nossa visão de mundo e ter outras perspectivas acerca do nosso próprio papel neste universo: o estudo da astronomia é, de certo modo, uma lição de humildade (SAGAN, 2019). A História da Astronomia revela que a preocupaçáo com os movimentos dos corpos celestes (Sol, Lua, planetas, estrelas, cometas etc.) remonta às civilizaçóes da antiguidade e até mesmo à pré-história: neste caso específico temos o campo da arqueoastronomia, que estuda as formas como no passado, em tempos pré-históricos, as pessoas compreendiam os fenômenos do céu, como elas usavam estes fenômenos para atender a objetivos específicos e qual o papel que o céu desempenhava em suas culturas (BROSH, 2011).

Um problema que surgiu longo nos primeiros séculos da civilização egípcia na antiguidade, no decorrer do terceiro milênio a.C., foi sobre a determinação de quantos dias tinha um ano, problema este que foi resolvido a partir do desenvolvimento da observação atenta e metódica acerca dos astros do céu noturno, em particular, das observaçôes realizadas no chamado dia do nascimento heliacal da estrela Sirius (a mais brilhante de todas as estrelas), definido como o dia em 
que Sirius surge no horizonte, no céu noturno, momentos antes do Sol ("Hélio") nascer (JONG, 2006): foi assim que há aproximadamente 5 mil anos, os egípcios conseguiram determinar que a duraçáo do ano era de aproximadamente 365 dias, um feito que pode ser considerado notável para a sua época. Questóes como esta, relacionadas aos primórdios da história da astronomia, mostram que mesmo as perguntas mais simples podem servir como problematizadoras e propulsoras do processo de aprendizagem.

O consenso científico contemporâneo aponta que o Universo surgiu a partir de um ponto primordial, há cerca de 14 bilhôes de anos (DAMINELI; STEINER, 2010) e vem se expandindo desde entáo: a formação das estrelas ocorreu a partir de aglomerados de partículas e poeiras em nebulosas, no meio interestelar, constituído principalmente de hidrogênio (FRAZZOLI, 2012). Estes aglomerados, pela própria força de gravidade, começaram a se contrair e a estruturar "caroços" que são os embriōes de estrelas em formação. Nós somos feitos - dentre outros elementos constituintes - de carbono, oxigênio e nitrogênio, átomos que não existiam inicialmente no universo, mas que foram sendo criados no interior das estrelas, a partir de reaçóes de fusão nuclear (MILANI et al., 2012). Além disso, eventos de explosão de estrelas, conhecidos como supernovas, expelem materiais que encontram outros dejetos oriundos da fusão nuclear nas estrelas que estão espalhados pelo universo, propiciando a formação de novas estrelas e de estruturas como os sistemas planetários. Atualmente descobrimos alguns milhares de exoplanetas orbitando em torno de outras estrelas (HOWELL, 2018), inclusive alguns deles podem ter água em estado líquido, como acontece na Terra, pois estáo na chamada zona de habitabilidade.

Conhecimentos de astrofísica e cosmologia, como estes acima, sobre a evolução do Universo e acerca da formação (cosmogênese) dos elementos são importantes que sejam conhecidos e apropriados pelos cidadãos leigos, pois ajudam no processo de alfabetizaçáo científica, colaboram para a ampliação da visão do mundo, democratizam o acesso à ciência de fronteira e permitem uma compreensão mais realista sobre os métodos usados pelos cientistas para a construção de conhecimentos científicos.

A aprendizagem de conteúdos relacionados à astronomia acontece tanto na chamada educação formal (no âmbito de diferentes disciplinas, como é o caso da física), quanto em atividades cujo objetivo é tornar determinados assuntos científicos acessíveis à população em geral, atividades estas que recebem várias denominaçóes, tais como divulgação, popularização, disseminação e difusão da ciência (LANGHI; NARDI, 2009), sendo que a expressão divulgação científica é a mais utilizada no Brasil (MARANDINO et al., 2004). A divulgação científica na área da astronomia é um campo que conta, em diferentes regiōes e países do mundo, com muita diversidade e com bastante protagonismo, sendo realizada geralmente por profissionais dedicados e entusiastas (MARQUES, 2017): para este processo se efetivar são utilizados diferentes recursos, técnicas, processos e produtos (BUENO, 2010). 
Devido ao caráter inerentemente interdisciplinar da astronomia, é possível trabalhar conceitos que estão relacionados a outras ciências, o que favorece uma visão mais integradora acerca do conhecimento científico, desperta habilidades de observação, estimula a formação do senso crítico e sensibiliza as pessoas para uma reflexão mais embasada cientificamente sobre questóes cósmicas acerca da existência, da origem e da evolução do universo (CARNEIRO; LONGHINI, 2015).

\section{SIMULAÇÓES}

Uma simulaçáo é um programa de computador que tenta modelar um sistema natural específico, no âmbito do qual os usuários podem manipular as variáveis do modelo para verificar como ele se comporta em diferentes condiçóes, de modo que o resultado dessas alteraçóes seja informado pelo programa. Algumas simulaçóes de computador são particularmente valiosas para professores de ciências, pois ajudam os alunos a visualizarem aspectos da ciência geralmente inacessíveis, em escalas muito grandes (cósmicas) ou muito pequenas (subatômicas), escalas essas que implicam na dificuldade - e, às vezes, na impossibilidade - de serem vistas com nossos olhos, mesmo com o uso de instrumentos de medida poderosos, como microscópios e telescópios.

Programas de simulação são, portanto, recursos didáticos bastante adequados para testar hipóteses, para verificar com rapidez certas ideias e para estudar a forma pela qual uma grandeza depende de certas variáveis, comportamento este que é revelado por meio de gráficos ou figuras, algo que ajuda na compreensão de muitos conceitos científicos considerados geralmente abstratos e complexos por muitos alunos (KHAN, 2010).

As simulações são recursos de aprendizagem altamente eficazes, mas elas são apenas ferramentas e não podem substituir um bom professor que planeje as situações de aprendizagem mais adequadas para serem usadas e que oriente os alunos durante o processo de ensino (WIEMAN et al., 2010). Uma boa estratégia para o seu uso implica em definir previamente os objetivos específicos da aprendizagem, em compreender os conhecimentos prévios dos alunos e em encorajar os estudantes a criarem sentido sobre os conceitos que estão aprendendo. Práticas interativas propiciadas pelas simulaçôes desenvolvem também uma dimensão cooperativa ao processo de aprendizagem que é fundamental para o desenvolvimento intelectual e o crescimento coletivo de um grupo de alunos (AGYEL; JITA; JITA, 2019).

Em particular, no processo de desenvolvimento desta investigação três softwares de simulação foram utilizados em atividades de divulgação científica e são discutidos neste artigo: o "Stellarium", o "Monte um átomo" do "PhET Interactive Simulations" e "Exoplanet Transit Hunt". Abaixo, serão discutidas, de modo breve, as principais características de cada uma destas simulaçóes.

O "Stellarium" é um software de código aberto (https://stellarium.org/pt/) e de acesso gratuito que tem como principal objetivo simular os astros no céu em tempo real, equiparando-se à ideia de um planetário pessoal que permite que o 
usuário observe estrelas, constelaçóes, planetas, nebulosas e outros corpos celestes na tela do seu computador. Pelo uso do Stellarium é possível "se locomover" para diferentes locais do universo por meio da ferramenta de zoom, aproximando-se ou afastando-se do corpo celeste a ser observado. Esse programa permite também que sejam alteradas as coordenadas do ponto de observação da Terra (latitude e longitude), de modo semelhante ao recurso Street View utilizado no "Google Maps". Outra ferramenta característica do programa Stellarium é o controle do tempo, pois é possível adiantar, retroceder ou parar o tempo, possibilitando a realizaçáo de diferentes tipos de experiências educacionais envolvendo a história da astronomia, tendo em vista que isso nos permite voltar a datas importantes historicamente, relativas a fatos que ocorreram em diferentes locais do globo terrestre: este foi o caso, por exemplo, das observaçôes realizadas pelo físico e matemático Galileu Galilei em 1610, ao estudar as luas de Júpiter, em Veneza, na Itália. Uma atividade deste tipo foi realizada para alunos das escolas da região, em algumas das açôes de extensão de divulgação científica que ocorreram, pela alteração da contagem do tempo do Stellarium para mais de quatro séculos no passado. O Stellarium pode ser baixado para o computador, mas também pode ser usado diretamente na web pelo navegador.

Figura 1: Tela do simulador "Stellarium".

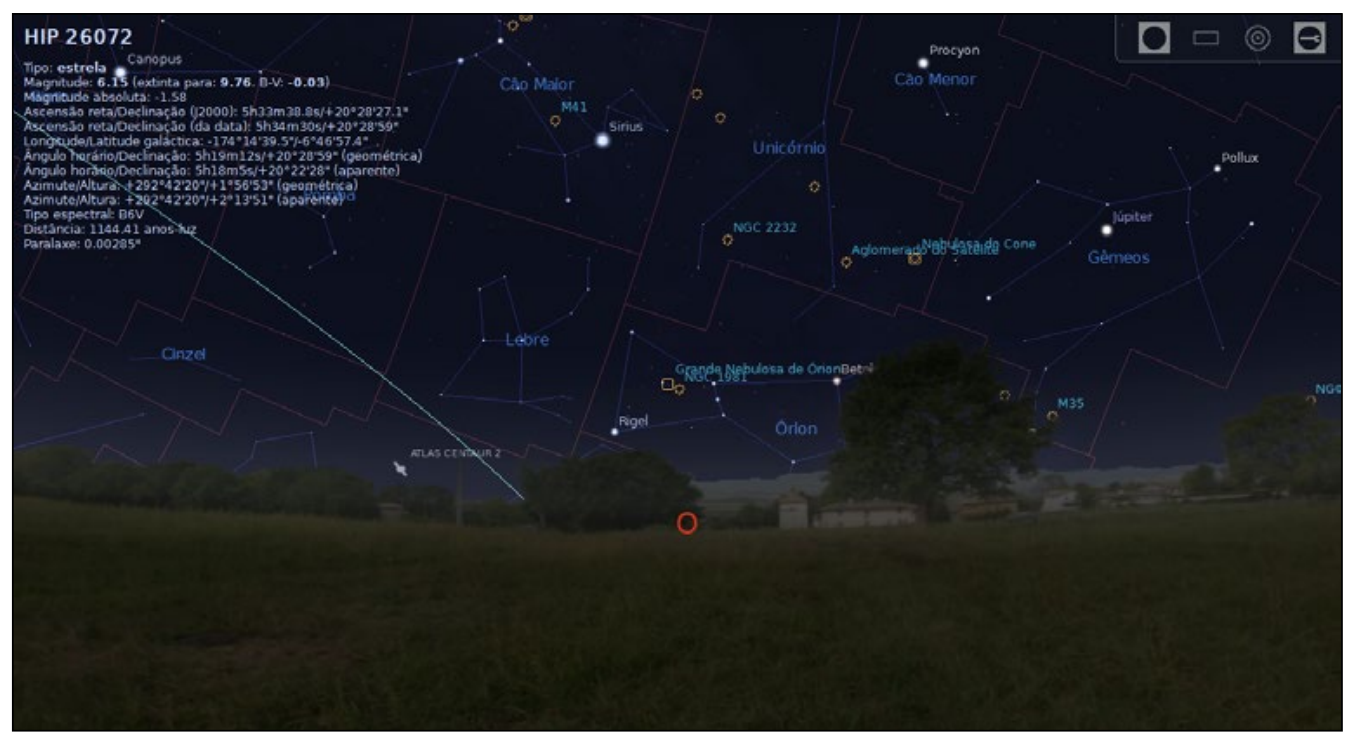

Fonte: Elaboradas pelos autores (2021).

A simulação de acesso gratuito "Monte um Átomo", do site "PhET Interactive Simulations" da Universidade de Colorado (https://phet.colorado.edu/pt_BR/ simulation/build-an-atom), proporciona uma maneira didática (interativa e visual) de se estudar as principais características do modelo atômico proposto pela física moderna nas primeiras décadas do século XX. Na prática, a observação direta do átomo está fora do contexto visual de qualquer ser humano, mas recursos didáticos 
como esse, permitem superar tal dificuldade. Sendo assim, esta ferramenta possibilita "construir" um átomo, variando-se o número de suas partículas constituintes (prótons, nêutrons e elétrons); em cada etapa de construçáo é possível pensar sobre o que ocorre com o equilíbrio do núcleo atômico quando se tem a adição ou a subtraçáo de prótons e nêutrons, por exemplo. A partir dessa perspectiva, torna-se realizável a construção dos átomos mais leves da tabela periódica (até o número atômico 10), o que pode proporcionar uma rica discussão a respeito do número de massa e do número atômico de um átomo, da estabilidade nuclear e da carga total do átomo, temas que são de grande importância para a Astrofísica Nuclear, em particular no caso do estudo da formação ou cosmogênese dos elementos dentro das estrelas.

Figura 2: Tela do simulador "Monte um átomo" do site "PhET Interactive Simulations"

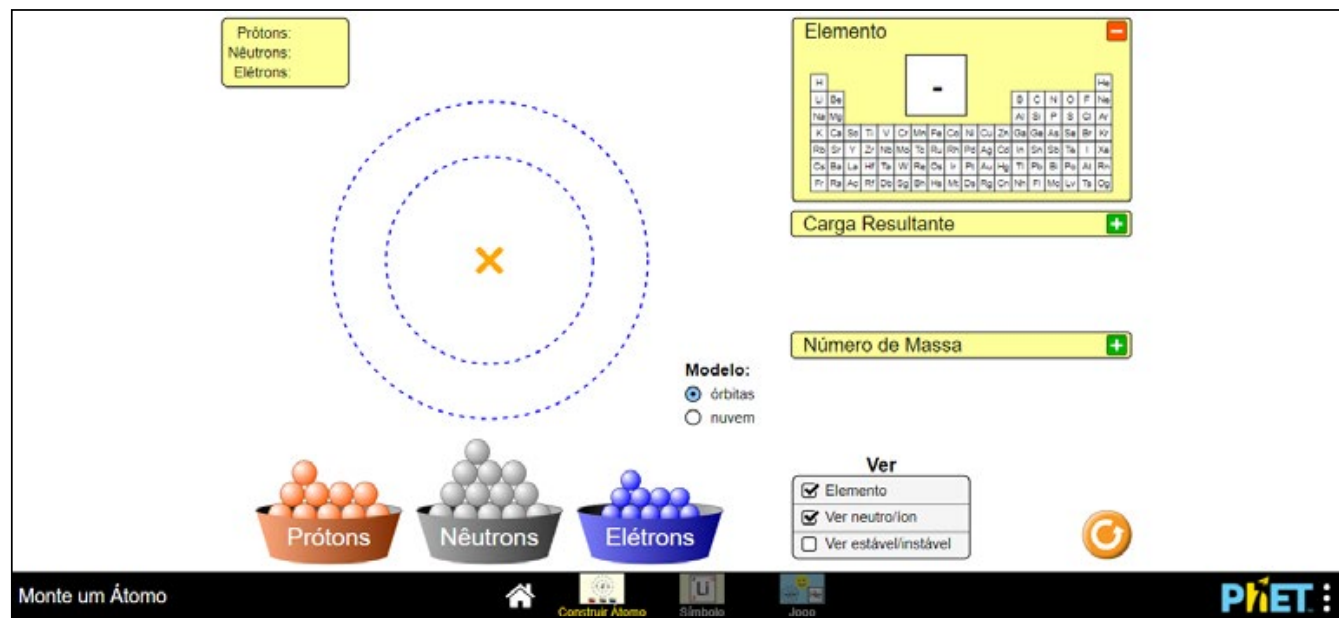

Fonte: Elaboradas pelos autores (2021).

Finalmente, o "Exoplanet Transit Hunt" (em tradução livre, "Caça de Exoplanetas em Trânsito”) é um software de acesso gratuito, disponível na internet no link http://www.planetarium-activities.org/shows/sp/exoplanet-transit-hunt e que foi elaborado pela Universidade da Califórnia em Berkeley, dentro do projeto intitulado "Planetarium Activities for Successful Shows" (PASS), que possui uma série de atividades referentes à área de astronomia, com foco no estudo de exoplanetas. Este software tem por finalidade apresentar uma simulação de uma detecção de um exoplaneta pelo método de trânsito - também conhecido como de "eclipse planetário" - que ocorre quando o planeta, ao transitar em sua órbita pela frente da sua estrela hospedeira (ao longo da nossa linha de visáo), produz uma queda minúscula, mas mensurável, da intensidade do brilho da estrela, fornecendo dados importantes sobre ele e sobre a estrela em torno da qual orbita. A interface inicial desse programa permite observar o fenômeno da queda da intensidade do brilho da estrela seguida de uma breve explicação do método. A partir de um catálogo, o 
usuário escolhe uma estrela que será seu objeto de estudo. A simulação é realizada e são anotados os dados obtidos em um "caderno de notas", disponível na parte inferior da interface do programa. Ao coletar esses dados, passa-se para outras etapas que utilizam esses dados para a obtenção de características referentes ao exoplaneta e sua estrela. Ao completar o "caderno de notas", com todas as informações que foram previamente calculadas ao longo da sua utilização, o programa apresenta uma imagem digitalizada da suposta superfície desse planeta e o compara com a Terra. A determinação da posição de cada planeta na órbita do seu sistema estelar permite observar se ele se encontra em uma zona habitável - regiâo ao redor da estrela com condiçóes necessárias para a presença de água líquida - permitindo discussóes sobre a questão da existência de vida fora do planeta Terra, relacionada à área da astrobiologia (KANE; GELINO, 2012).

Figura 3: Tela do simulador "Exoplanet Transit Hunt".

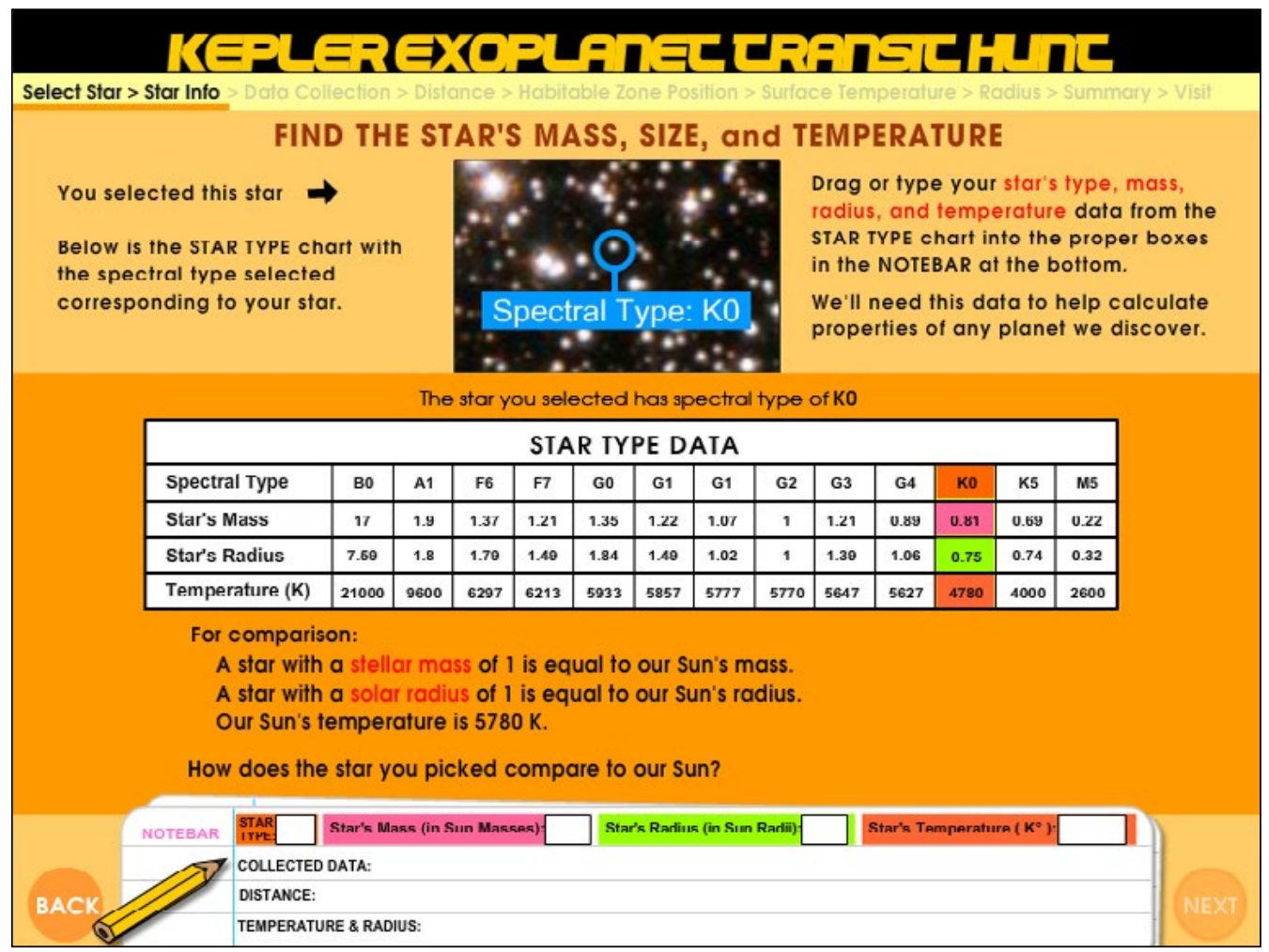

Fonte: Elaboradas pelos autores (2021).

Estas três simulaçóes abordam fenômenos diversificados e contam com recursos diferentes para a sua manipulaçáo, mas todas elas apresentam características úteis para promoverem processos de aprendizagem que envolvam os alunos, estimulem a participação e despertem a curiosidade e a vontade por saber mais sobre os fenômenos estudados. 


\section{ATIVIDADES DE DIVULGAÇÃO CIENTÍFICAS REALIZADAS COM USO DE SIMULAÇÓES}

Diversas atividades de divulgação científica a respeito de temas de astronomia, astrofísica e cosmologia - permeadas pelo uso de programas de simulação como ferramentas didáticas - foram realizadas pelos autores deste trabalho, em 2018 e em 2019, em diferentes espaços de instituiçôes de ensino do litoral norte paulista: a experiência desenvolvida no transcorrer do processo de realizaçáo destas açóes permitiu um conhecimento mais aprofundado acerca do uso de softwares com objetivos educacionais. Este trabalho ocorreu no âmbito das açóes de extensão desenvolvidas junto à comunidade externa pelo campus de Caraguatatuba do Instituto Federal de São Paulo (IFSP). Em cada uma destas apresentaçóes, foram usados pelo menos um dos três softwares de simulação que são foco específico desta investigação: o "Stellarium", o "Monte um átomo" do "PhET Interactive Simulations" e "Exoplanet Transit Hunt". Destes três programas, o primeiro e o último são diretamente relacionados a conhecimentos de astronomia. Já o segundo programa aborda uma temática que está na interface entre a física atômica e a química, entretanto, a simulação para montar átomos com números atômicos entre 1 e 10 pode ser usada para explicar os mecanismos de formação dos átomos mais leves pelas reaçóes de fusão nuclear que ocorrem dentro de estrelas, conteúdo este associado à disciplina de astrofísica.

As apresentaçóes de divulgação científica que foram realizadas tiveram como eixo condutor temas relacionados à astronomia, tais como a detecção de exoplanetas, o ciclo de vida das estrelas e os conhecimentos astronômicos desenvolvidos no passado por diferentes civilizaçóes e culturas. Um ponto em comum, era que elas procuraram sempre contextualizar historicamente os conhecimentos abordados. Estas apresentaçôes eram previamente agendadas com professores ou gestores de escolas públicas parceiras do IFSP-Caraguatatuba e tinham como um dos seus objetivos principais despertar o interesse dos alunos presentes para o estudo de conteúdos científicos, particularmente de física e de astronomia. Os educadores destas instituiçóes de ensino selecionavam entre 20 e 40 alunos para participarem das apresentaçóes; um dos critérios usados pelos professores era escolher para participar das atividades, aqueles alunos que apresentassem um maior interesse por temas relacionados às ciências naturais. As apresentaçôes foram feitas em salas das escolas visitadas que não tivessem muita claridade natural (para propiciar uma melhor visibilidade aos slides) e que fossem razoavelmente silenciosas; os equipamentos utilizados e disponibilizados pelas próprias escolas, foram um projetor de slides (datashow) acoplado a um computador e a uma caixa de som e uma tela (ou parede branca) adequada para a projeção de imagens.

A elaboração destas apresentaçóes de divulgação científica envolvia a sua estruturação na forma de um arquivo para a exibição de imagens e slides, do tipo do powerpoint. Para a fundamentação teórica acerca da ciência envolvida, foram consultados artigos de referência, livros e manuais didáticos com informaçôes atualizadas a respeito dos temas abordados. Uma preocupação sempre presente foi 
com o processo de transposiçáo didática, ou seja, com a tentativa de traduzir o conhecimento científico sistematizado de modo a torná-lo o mais compreensível para estudantes da educação básica em geral, sem, obviamente, descaracterizá-lo. Em alguns momentos, o uso de vídeos curtos associados aos temas trabalhados foi usado como ferramenta complementar. A inclusão nas atividades das simulaçóes citadas anteriormente - "Stellarium", "Monte um átomo" (do PhET) e "Exoplanet Transit Hunt" - como recursos para ajudar os alunos a compreenderem melhor os conceitos científicos em questão, constituiu-se em um diferencial bastante positivo destas apresentaçóes, como ficou nítido tanto pelo envolvimento e pelas intervençóes dos alunos durante as atividades, quanto pelos depoimentos deles e de seus professores, fornecidos após o término de cada uma das apresentaçóes.

\section{RESULTADOS}

$\mathrm{O}$ interesse dos alunos a respeito das simulaçóes ficou evidente pelos seus impactos no contexto das apresentações de divulgação científica implementadas: uma característica destas simulaçôes é que elas são acessíveis e gratuitas a qualquer pessoa com um computador com acesso à internet, o que serviu como estímulo a muitos alunos que procuraram se informar acerca dos sites destas simulaçóes para poder interagir com elas após o final das atividades, em seus computadores pessoais, por exemplo, ou até mesmo, nos computadores existentes nas próprias instituiçóes de ensino em que estudavam.

As ações de divulgação científica realizadas procuraram ampliar o diálogo entre o saber científico sobre astronomia que é estudado e investigado academicamente (inclusive dentro do IFSP-Caraguatatuba) e o dia a dia dos jovens presentes nas atividades, de modo a aproximar o público das mais recentes descobertas científicas realizadas nesta área do conhecimento.

As observações metódicas feitas durante a implementação destas atividades de divulgação científica - juntamente com outros dados e informaçôes obtidos, por exemplo, por conversas estabelecidas com alunos e professores das escolas visitadas - permitiram notar a existência de um expressivo interesse pela aquisiçáo de conhecimentos atualizados sobre astronomia, cosmologia e astrofísica, por diversos dos alunos presentes.

As parcerias estabelecidas com professores de diversas escolas da região permitiram ampliar o leque de alunos interessados nas atividades de divulgação científica propostas, bem como conhecer melhor o perfil deste tipo de aluno. $\mathrm{O}$ IFSP-Caraguatatuba que abriga os cursos de licenciatura em física e em matemática, deste modo, também se beneficiou com este processo, pois a valorização das áreas científicas é um fator de motivaçáo para que jovens alunos vocacionados para a ciência e para a educaçáo avaliem a possibilidade de ingressar nestes cursos de graduação.

Vários dos ganhos observados com o uso de simulaçóes no processo de ensino-aprendizagem nas atividades de divulgaçáo científica realizadas estáo 
em concordância com a literatura científica existente a respeito (RUTTEN; JOOLINGEN; VEEN, 2012; PRICE; WIEMAN; PERKINS, 2019). Entre outros motivos, as simulaçóes usadas se provaram adequadas para atingir diversos objetivos, tais como: criar um ambiente de liberdade para a exploração de diferentes cenários e possibilidades; testar hipóteses que possam ser respondidas e verificar a validade de concepçóes errôneas; refletir sobre as características de um modelo científico e sobre os limites das simplificaçôes; fazer previsóes, justificar conclusóes e discutir acerca das suas implicações no mundo real; compreender sobre como as diferentes variáveis afetam um fenômeno e sobre quais as relaçôes existentes entre as variáveis envolvidas; organizar as informaçóes de um modo que ajude a interpretá-las e criar representaçóes gráficas dos dados quantitativos existentes; visualizar mecanismos subjacentes a certos fenômenos; decidir entre duas diferentes explicaçóes ou modelos; gerar questôes que possam ser um ponto de partida para reflexóes fecundas; tornar os alunos ativos e engajados no seu próprio processo de aprendizagem; possibilitar a experiência da sensação de prazer associada ao processo de descoberta; perceber de modo mais real a forma como ocorre o processo de produção de conhecimentos científicos.

\section{CONSIDERAÇÓES FINAIS}

Durante as atividades de divulgação científica empreendidas, foi possível perceber uma interrelação muito positiva entre os temas relacionados à astronomia escolhidos para serem abordados e os três programas com simulaçóes selecionados para colaborarem nas explicaçóes acerca dos conceitos científicos envolvidos: o "Stellarium", o "Monte um átomo" do "PhET - Interactive Simulations" e "Exoplanet Transit Hunt". Estas são três simulaçôes de acesso livre e gratuito que estão disponíveis para serem usadas na internet por qualquer interessado: apesar de terem diferentes características, todas as três se mostraram como recursos didáticos valiosos para situaçóes de aprendizagem acerca de tópicos científicos relacionados à disciplina da astronomia. O uso das simulaçóes ajudou que os alunos tivessem uma postura mais ativa durante as apresentaçôes, estabelecendo conjecturas, testando hipóteses, verificando as relaçóes entre as grandezas envolvidas e refletindo acerca de explicaçôes científicas sobre os fenômenos estudados que estivessem ancoradas em evidências experimentais e no raciocínio lógico.

O uso das simulações nas ações de divulgação científica realizadas permitiu que os alunos conseguissem identificar com mais nitidez as informaçóes que eram mais relevantes para a compreensão de um certo fenômeno em termos científicos, em relação aos dados que influenciavam menos o comportamento observado para um determinado fenômeno (PFEFFEROVÁ, 2015). Além disso, a aprendizagem mais ativa pelos alunos, possibilitada pelo uso de simulaçóes, levou à apropriação efetiva de novos conhecimentos embasados cientificamente e que passaram a ser usados para a compreensão da realidade. As simulaçóes também colaboraram para incrementar a criatividade e a capacidade de imaginação dos alunos acerca de diferentes aspectos dos fenômenos abordados nas atividades de divulgação científica 
realizadas, o que contribui para uma melhor compreensão dos conceitos científicos envolvidos (TAWIL; DAHLAN, 2017).

A organizaçáo de atividades de divulgação da ciência sobre astronomia em escolas de educação básica da região do litoral norte paulista se mostrou um processo proveitoso, em diferentes aspectos, para todos os envolvidos. $\mathrm{O}$ estreitamento das relaçôes entre a instituição formadora de professores de física e de matemática (o IFSP-Caraguatatuba) e a rede de escolas públicas estaduais e municipais foi um ganho importante. A aproximação produzida entre os estudantes universitários do IFSP-Caraguatatuba e os estudantes das escolas públicas de ensino médio e dos últimos anos do ensino fundamental da região, produziu efeitos positivos para a formaçáo de todos os discentes envolvidos.

Muitas vezes, as atividades de divulgaçáo da ciência se limitam aos espaços acadêmicos, dentro das instituiçôes universitárias, por exemplo, atingindo apenas aqueles mesmos grupos e pessoas que já têm laços mais estreitos e uma maior proximidade com a produção da ciência. As açóes realizadas aconteceram em espaços das escolas de educação básica e se embasaram na concepção de que a divulgação científica tem um papel relevante na intermediação necessária entre ciência e sociedade. Elas tornaram clara a importância de serem desenvolvidas mais pesquisas educacionais acerca desta área, para investigar os modos como o conhecimento "flui" pelos diversos grupos e classes sociais e as formas como as representaçóes acerca da ciência são produzidas e se disseminam (CARNEIRO; LONGHINI, 2015).

Algo que ficou evidente no transcorrer das atividades realizadas é a necessidade de que as açôes de divulgação sobre astronomia procurem tanto combater as concepçóes espontâneas equivocadas, os erros conceituais e os mitos que são comuns entre o público leigo (LANGHI; NARDI, 2009), quanto democratizar o acesso à ciência para que a posse de conhecimentos náo fique nas mãos de poucos, o que pode se tornar sinônimo de concentração de poder, de dominação social e de desigualdades sociais. A divulgação científica acerca de temas de astrofísica e cosmologia, permitiu também discutir em paralelo conceitos relacionados à Física Moderna e Contemporânea, uma área da Física bastante relevante para a formação dos alunos (MARQUES; SILVA, 2006).

O trabalho realizado indicou que é crucial que seja estimulado o ativismo e engajamento por parte de professores universitários, pesquisadores e divulgadores da ciência em prol da popularização dos conhecimentos sistematizados contemporaneamente na astronomia, na astrofísica e na cosmologia, da forma mais ampla possível, para que a população como um todo possa ter acesso aos saberes produzidos pelo esforço intelectual coletivo da humanidade. As açóes de divulgação científica realizadas permitiram notar que, de fato, para muitos jovens, a astronomia é altamente motivadora. As experiências vivenciadas na realização de apresentaçóes de disseminaçáo de conhecimentos de astronomia pelo uso de simulaçóes revelaram um interesse surpreendentemente alto por assuntos situados na fronteira da ciência atual. 
O "laboratório" natural para o ensino de astronomia, o céu, está disponível a todos os interessados, o que favorece muito o desenvolvimento da cultura científica, de habilidades de observaçáo e da aprendizagem acerca dos métodos usados pela ciência para formular conclusóes a respeito do universo e inferir os princípios e leis que regem a natureza.

Popularizar conteúdos associados à astronomia para alunos da educação básica, por meio de simulaçôes gratuitas e de fácil acesso, teve como um dos mais relevantes resultados instigar, nos jovens em geral, a curiosidade pela ciência e pela pesquisa acadêmica. As açóes implementadas identificaram a importância de os alunos terem um papel mais ativo no processo de ensino, o que pode ocorrer por meio da interação com softwares de simulação. O diálogo estabelecido com a comunidade externa abriu oportunidades educacionais e permitiu cumprir os três papéis de toda instituiçáo de caráter universitário (como é o caso do IFSP): ensino, pesquisa e extensão. Um dos resultados adicionais da realizaçáo deste trabalho foi perceber que o interesse existente por astronomia entre o público em geral pode ser usado para alavancar propostas de ensino e materiais didáticos que contribuam para que os jovens egressos da educação básica possuam uma formação científica mais sólida e bem fundamentada.

\section{AGRADECIMENTOS}

Agradecemos ao IFSP e ao CNPq pelo financiamento desta pesquisa.

\section{REFERÊNCIAS}

AGYEL, Elizabeth Darko; JITA, Thuthukile; JITA, Loyiso C. Examining the effectiveness of simulation-based lessons in improving the teaching of high school physics: ghanaian pre-service teachers' experiences. Journal of Baltic Science Education, v. 18, n. 6, p. 816-832, 2019. Disponível em: http://www.scientiasocialis.lt/jbse/files/pdf/vol18/816832.Agyei_JBSE_Vol.18_No.6.pdf. Acesso em: 23 fev. 2021.

BRADLEY, Paul. The history of simulation in medical education and possible future directions. Medical Education, n. 40, p. 254-262, 2006.

BROSH, Noah. Thinking about Archeoastronomy. ArXiv, 2011. Disponível em: https://arxiv.org/abs/1103.5600. Acesso em: 27 fev. 2021.

BUENO, Wilson Costa. Comunicação científica e divulgação científica: Aproximaçôes e rupturas conceituais. Informaçáo \& Informaçáo, Londrina, v. 15, n. 1, p. 1-12, 2010. Disponível em: http://www.uel.br/revistas/uel/index.php/informacao/article/view/6585. Acesso em: 28 fev. 2021.

CARNEIRO, Dalira Lúcia Cunha Maradei; LONGHINI, Marcos Daniel. Divulgação científica: as representaçóes sociais de pesquisadores brasileiros que atuam no campo da astronomia. Revista Latino-Americana de Educação em Astronomia - RELEA, n. 
20, p. 7-35, 2015. Disponível em: https://www.relea.ufscar.br/index.php/relea/article/ view/204/307. Acesso em: 26 fev. 2021.

CHASSOT, Attico. Alfabetização científica: uma possibilidade para a inclusão social. Revista Brasileira de Educação, n. 22, p. 89-100, 2003. Disponível em: https://www. scielo.br/pdf/rbedu/n22/n22a09.pdf. Acesso em: 25 fev. 2021.

DAMINELI, Augusto; STEINER, João. O fascínio do universo. São Paulo: Odysseus, 2010.

FLATO, Uri Adrian Prync; GUIMARÃES, Helio Penna. Educação baseada em simulação em medicina de urgência e emergência: a arte imita a vida. Revista Brasileira de Clínica Médica, São Paulo, v. 9, n. 5, p. 360-364, 2011. Disponível em: http://files.bvs.br/ upload/S/1679-1010/2011/v9n5/a2250.pdf. Acesso em: 23 fev. 2021.

FRAZZOLI, Jean Carlo Feital. Astrofísica de estrelas compactas como atividade suplementar para o ensino médio. Rio de Janeiro: Dissertação de Mestrado UFRJ, 2012. Disponível em: https://www.if.ufrj.br/ p pef/producao_academica/ dissertacoes/2012_Jean_Frazzoli/dissertacao_Jean_Frazzoli.pdf. Acesso em: 26 fev. 2021.

HOWELL, Elizabeth. Exoplanets: Worlds Beyond Our Solar System. March 29, 2018. Disponível em: https://www.space.com/17738-exoplanets.html. Acesso em: 01 set. 2018.

JONG, Teije de. The heliacal rising of Sirius. In: HORNING, E.; KRAUSS, R.; WARBURTON, D. A. (editors). Ancient Egyptian Chronology, Handbook of Oriental Studies, v. 83, p. 432-438, 2006. Disponível em: https:/www.researchgate.net/ publication/275033106_The_Heliacal_Rising_of_Sirius. Acesso em: 27 fev. 2021.

KANE, Stephen R.; GELINO Dawn M. The Habitable Zone Gallery. Publications of the Astronomical Society of the Pacific, v. 324, p. 323-328, 2012. Disponível em: https://iopscience.iop.org/article/10.1086/665271/pdf. Acesso em: 28 fev. 2021.

KHAN, Samia. New Pedagogies on Teaching Science with Computer Simulations. Journal of Science Education and Technology, v. 20, p. 215-232, 2011. Disponível em: https://link.springer.com/article/10.1007/s10956-010-9247-2. Acesso em: 23 fev. 2021.

LANGHI; Rodolfo; NARDI, Roberto. Ensino da astronomia no Brasil: educação formal, informal, não formal e divulgação científica. Revista Brasileira de Ensino de Física, v. 31, n. 4, 4402, 2009. Disponível em: https:/www.scielo.br/pdf/rbef/v31n4/v31n4a14. Acesso em: 27 fev. 2021.

MARANDINO, Martha et al. A Educação não formal e a divulgação científica: o que pensa quem faz? Atas do IV Encontro Nacional de Pesquisa em Ensino de Ciências (ENPEC), Bauru, 2004. Disponível em: http://paje.fe.usp.br/estrutura/geenf/textos/ oquepensa_trabcongresso5.pdf. Acesso em: 25 fev. 2021.

MARQUES, Adílio Jorge; SILVA, Cláudio Elias da. É possível uma iniciação científica no ensino médio como projeto para a divulgação da Física Moderna e Contemporânea? 
Revista de Educação em Ciências e Matemática, v. 2, p. 9-13, 2006. Disponível em: https://www.periodicos.ufpa.br/index.php/revistaamazonia/article/view/1671/2066. Acesso em: 27 fev. 2021.

MARQUES, Joana Brás Varanda. Educação Não-Formal e Divulgaçáo de Astronomia no Brasil: Atores e Dinâmica da área na Perspectiva da Complexidade. São Carlos: Tese de Doutorado - UFSCar, 2017. Disponível em: https://repositorio.ufscar.br/bitstream/ handle/ufscar/9613/MARQUES_Joana_2018.pdf?sequence=4\&isAllowed=y. Acesso em: 23 fev. 2021.

MILANI, Nikele. Química estelar e estrelas apocalípticas: estudo comparativo. 2012. Colloquium Exactarum, v. 4, n.2, p. 37-46, 2012. Disponível em: http://revistas. unoeste.br/index.php/ce/article/view/843. Acesso em: 23 fev. 2021.

MIRANDA, Guilhermina Lobato. Limites e possibilidades das TIC na educação. Sísifo Revista de Ciências da Educaçáo, n. 3, p. 41-50, 2007. Disponível em: http://ticsproeja. pbworks.com/f/limites+e+possibilidades.pdf. Acesso em: 21 fev. 2021.

PFEFFEROVÁ, Miriam Spodniaková. Computer Simulations and their Influence on Students' Understanding of Oscillatory Motion. Informatics in Education, v. 14, n. 2, 279-289, 2015. Disponível em: https://files.eric.ed.gov/fulltext/EJ1079075.pdf. Acesso em: 25 fev. 2021.

PRICE, Argenta; WIEMAN, Carl; PERKINS, Katherine. Teaching with simulations. The Science Teacher, v. 86, n. 7, p. 46-52, 2019. Disponível em: https://www.oeconsortium.org/wp-content/uploads/gravity_forms/16c1480780880d51a4fc44ed750d41335f/2019/05/2019_03_TST_PhET_ TeachingPractices.pdf. Acesso em: 28 fev. 2021.

RIBEIRO, Angela A.; GRECA, Ileana M. Simulações computacionais e ferramentas de modelização em educação química: uma revisão de literatura publicada. Química Nova, v. 26, n. 4, p. 542-549, 2003. Disponível em: http:/quimicanova.sbq.org.br/detalhe_artigo. asp?id=4640. Acesso em: 25 fev. 2021.

RUTTEN, Nico; JOOLINGEN, Wouter R. van; VEEN, Jan T. van der. The learning effects of computer simulations in science education. Computers \& Education, v. 58, n. 1, p. 136-153, 2012. Disponível em: https://www.researchgate.net/ publication/216743334_The_learning_effects_of_computer_simulations_in_science_ education. Acesso em: 23 fev. 2021.

SAGAN, Carl. Pálido Ponto Azul. São Paulo: Companhia das Letras, 2019.

SANTOS, G.; OTERO, M. R.; FANARO, M. de los A. ¿Como Usar Software de Simulación en Clases de Física? Caderno Catarinense de Ensino de Física, Florianópolis, v. 17, n. 1, p. 50-66, abr. 2000. Disponível em: https://periodicos.ufsc.br/index.php/ fisica/article/view/6785. Acesso em: 26 fev. 2021. 
TAWIL, Muhammad; DAHLAN, Ahmad. Developing Students' Creativity through Computer Simulation Based Learning in Quantum Physics Learning. International Journal of Environmental \& Science Education, v. 12, n. 8, p. 1829-1845, 2017. Disponível em: http://eprints.unm.ac.id/3944/1/Developing\%20Student\%20Creativity. pdf. Acesso em: 28 fev. 2021.

WIEMAN, Carl et al. Teaching physics using PhET simulations. The Physics

Teacher, v. 48, n. 4, p. 225-227, 2010. Disponível em: https://www.researchgate.net/ publication/238560172_Teaching_Physics_Using_PhET_Simulations. Acesso em: 27 fev. 2021. 